Supporting Information

\title{
"A microfluidic chip for the photocatalytic production of active chlorine"
}

Sait Elmas, Filip Ambroz, Dipankar Chugh and Thomas Nann*

Preparation of the calibration curve:

The calibration curve was prepared by making a dilution series of $10 \mathrm{mg}$ methyl orange (MO) powder in 1 litre $0.2 \mathrm{M} \mathrm{KCl}$ solution. The $\mathrm{pH}$ was set by adding drop-wise concentrated hydrochloric acid $(\mathrm{HCl})$ and $1 \mathrm{M}$ potassium hydroxide to the concentration series using a $\mathrm{pH}$ meter.

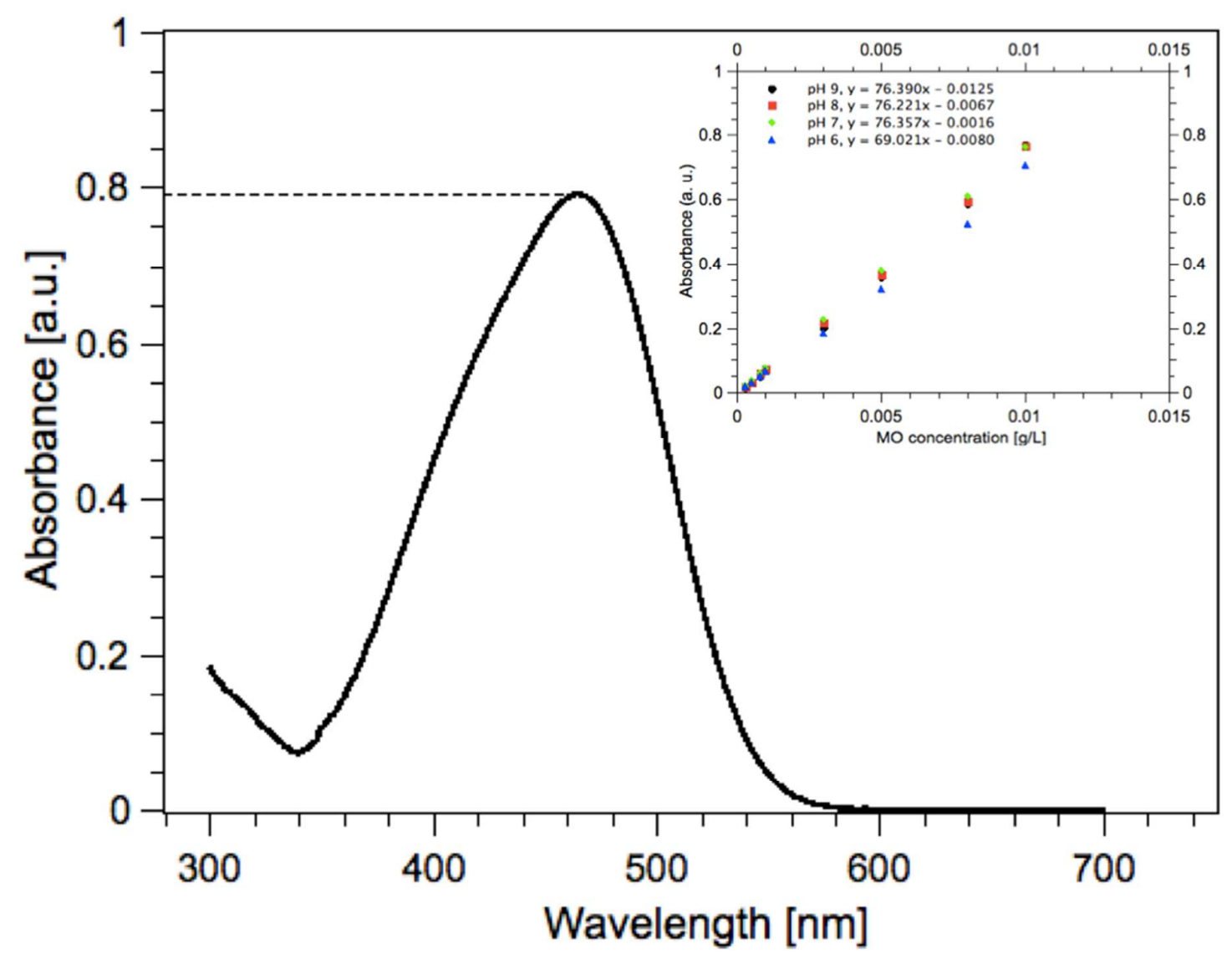

Figure S 1: Absorbance of $\mathrm{MO}$ in $0.2 \mathrm{M} \mathrm{KCl}$ after 30 minutes illumination on pure Au substrate. The inset shows the calibration curves between $\mathrm{pH} 6$ and 9 . $\mathrm{A} \mathrm{pH}$ of $6.8-7.0$ was measured for the $0.2 \mathrm{M} \mathrm{KCl}$ solution. 